\title{
10
}

\section{Incorporating Stakeholder Perspectives in Scenario Development}

\author{
Andrew Allan, Michelle Lim, and Emily J. Barbour
}

\subsection{Introduction}

The incorporation of stakeholder views is integral to the research from beginning to end and served a number of critical functions. Creating a clear link between research outputs and stakeholder needs was identified as an early priority giving stakeholders tangible input to and ownership of modelling and scenario processes. This component of the research places particular emphasis on stakeholder-identified issues and priorities to develop intervention recommendations that are relevant to both local

A. Allan $(\bowtie)$

School of Law, University of Dundee, Dundee, UK

M. Lim

Adelaide Law School, University of Adelaide, Adelaide, SA, Australia

E. J. Barbour

School of Geography and the Environment, University of Oxford, Oxford, UK 
users of ecosystem services and national decision-makers. For example, efforts to understand the reality of how legal, institutional and policy frameworks can mediate the translation of ecosystem services to benefits (see Chaps. 2 and 4) were driven in large part by stakeholders identifying key issues of interest during the early stages of the research.

A highly structured approach was accordingly adopted to ensure the ability to respond to stakeholder priorities and knowledge and ensure that stakeholder expectation of findings were realistic. In addition to the manifest need to match stakeholder needs with research capacity, the views of stakeholders are also integral to the scenario development process described in Chap. 9. This chapter describes the stakeholder engagement process as well as the first two stages of the four-stage scenario development process (see Fig. 10.1), identification of key issues and development of scenario narratives.

\subsection{Stakeholder Mapping}

Before elaborating further on the scenario development process, some background should be given regarding the rationale and methods used for incorporating stakeholder views. The increased use of stakeholder analysis in natural resource management reflects recognition of the extent to which stakeholders can influence the decision-making process (Prell et al. 2009). The identification, analysis and engagement of stakeholders are therefore central components of the research. Networks of stakeholders

\section{Baseline scenarios}

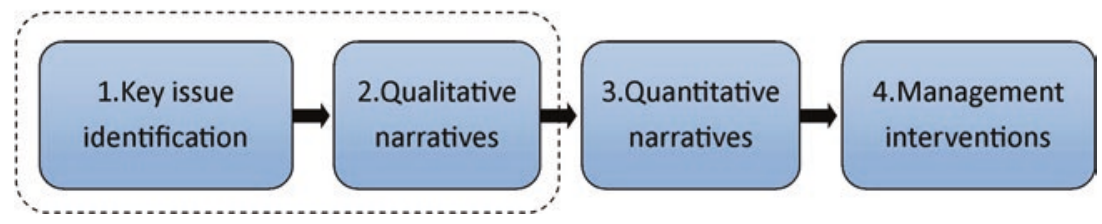

Fig. 10.1 The stages in scenario development highlighting the focus of this chapter 
were identified through interviews and stakeholder workshops involving government officials, local project partners, experts (e.g. academics) and Non-Governmental Organisations (NGOs).

Stakeholders were identified by way of an extensive mapping process (principally based on a snowball approach (Reed et al. 2009)). Additional stakeholders were identified at the more localised level (i.e. in the project case study areas in the Khulna and Barisal divisions). This process was bolstered through enhanced engagement with a small number of key stakeholders whose interests aligned most closely with the project from the perspective of use and uptake, data provision and cross-sectoral relevance. It became clear that for the mutual benefit of both the project and a small number of these key stakeholders, a more formal relationship would be preferable, and this resulted in the Water Resources Planning Organisation (WARPO) becoming a formal project partner and the establishment of a strategic alliance with the General Economics Division of the Planning Commission of the Government of Bangladesh.

Representatives from round 60 institutions were actively involved in the engagement between the project and relevant institutions across multiple scales in Bangladesh. Initially, this engagement primarily took the form of formal one-to-one interviews and latterly through more widely attended workshops. ${ }^{1}$ The range of stakeholders who were contacted by project partners and who chose to participate included the following:

- National government officials in a range of Ministries, the portfolios of which relate to ecosystem services and human well-being (e.g. Planning Commission; Ministry of Agriculture, WARPO)

- Relevant non- and inter-governmental organisations at the international level (e.g. International Union for Conservation of Nature (IUCN), International Organisation for Migration, Global Water Partnership, CARE)

- UN organisations, multi- and bi-lateral donor agencies (e.g. United Nations Development Programme (UNDP), World Health Organisation (WHO), World Food Programme (WFP), World Bank, Asian Development Bank) 
- National NGOs, research groups and subject experts, including representatives from academic institutions (e.g. BRAC and BRAC University, WildTeam, Bangladesh Agricultural Research Institute (BARI), Bangladesh Rice Research Institute (BRRI))

- Key informants, that is, those whose social/institutional positions give them specialist knowledge about other people, processes or happenings that is more extensive, detailed or privileged than ordinary people (Payne and Payne 2004)

The extent of engagement varied according to the relevance of individual stakeholders to the research: some agreed to individual interviews with a view to identifying the main issues of concern and others to attending the series of workshops that were held during the latter half of the research period.

\subsection{Identification of Key Issues}

An iterative approach was adopted to identify key issues of concern for stakeholders. This includes a review of relevant literature (i.e. academic papers, government legal and policy documents and available grey literature) and a series of workshops and unstructured interviews with national level stakeholders and other key informants. As shown in Table 10.1 (and further discussed in Allan et al. 2013), this process revealed the breadth of issues that needed to be addressed to effectively assess ecosystem service provision and human well-being. These represent a range of interlinked issues, challenges and uncertainties across the social, economic and environmental landscape of the study area.

Table 10.1 summarises the key issues, based on a synthesis and categorisation of issues identified in the literature, which also overlap those of stakeholder opinion. Issues identified in the literature that were not seen as priorities by stakeholders were therefore omitted from the list. Many stakeholder concerns mirror issues identified in the literature and underline the challenge of managing complex social-ecological systems. At this stage, the issues reflect the views of stakeholders and should not be taken to be a comprehensive and exhaustive categorisation of all the issues that may relate ecosystem services to livelihoods. 
Table 10.1 Key biophysical and socio-economic issues of importance as identified by stakeholders

\begin{tabular}{|c|c|}
\hline Socio-economic & Biophysical \\
\hline Food security & Salinisation \\
\hline Human-wildlife conflict & Riverbank erosion and sedimentation \\
\hline $\begin{array}{l}\text { Human-induced challenges to flow/ } \\
\text { freshwater availability }\end{array}$ & Arsenic \\
\hline Changes in livelihoods & Freshwater availability \\
\hline $\begin{array}{l}\text { Barriers to accessing ecosystem services } \\
\text { in the Sundarbans }\end{array}$ & Unpredictability of weather \\
\hline Migration & Extreme weather events \\
\hline Shrimp vs. crop & $\begin{array}{l}\text { Location of biggest embankments } \\
\text { (sea dykes)/coastal defence }\end{array}$ \\
\hline $\begin{array}{l}\text { Upstream/international issues } \\
\text { Availability of land }\end{array}$ & \\
\hline
\end{tabular}

\subsection{Scenario Development Process}

The rationale for adopting a scenario-based narrative approach of possible (and plausible) futures is that this allows responses to environmental and social changes over time to be explored in a way that addresses the significant levels of uncertainty. It also helps facilitate the integration of the views of stakeholders with the scientific findings, as well as their engagement in the assessment process.

In order to fully enable the connection between stakeholder priorities and the available modelling capacity, two separate stages are required: (i) to qualitatively describe what the future might look like at the scenario time horizon and (ii) to translate these qualitative descriptions into the quantitative form required by the numerical models. This section outlines the process adopted with respect to the first of these (the later stages are discussed in Chap. 9). The approach adopted was inspired by the shared socio-economic reference pathways (SSPs) approach (Arnell et al. 2011; O'Neill et al. 2012). Based on this, three socio-economic scenarios were developed for Bangladesh and coastal Bangladesh as devices for engaging with stakeholders: (i) Less Sustainable (LS), (ii) Business As Usual (BAU) and (iii) More Sustainable (MS). BAU was defined as the situation that might exist if existing policies were to 
continue and development trajectories proceed along similar lines to the previous 30 years or so, irrespective of whether or not this in itself is sustainable. LS and MS are alternative trajectories that are broadly less or more sustainable than BAU. This scenario elaboration approach effectively produces what Arnell et al. (2011) call 'extended SSPs' as it takes what is a global approach unsuited to direct application at the national level and, through the addition of more locally relevant characteristics, facilitates the downscaling of the SSPs. It also allowed the stakeholder issues of concern to be projected up to 2050, on the basis of the climate projections that used in the research (see Chap. 11).

In order to better facilitate the integration of stakeholder concerns with the development of scenario narratives, the issues were categorised into broad groups and further elaborated in accordance with stakeholder views as expressed at the first stakeholder workshop. This produced a consolidated list (see Table 10.2) that was used as the basis for downscaling.

Each of the resulting issues was categorised and, during a workshop held on 22-23 October 2013, broken down by participants into more than 100 separate elements. The meeting was attended by a total of around 35 people, representing donor organisations, government ministries and academic or sectoral experts across a wide spectrum of disciplines. Once agreement (consensus or majority agreement) was reached on the breakdown of each of the issues and categories, the groups were asked to assess the extent of the expected improvement or deterioration over time, using a scale from ' + ' to ' +++ ', with ' + ' being slight and ' +++ ' being strong (and with 'no change' comprising a seventh element of the scale). The result was a detailed and internally consistent matrix of how the participants believed society in the Ganges Brahmaputra Meghna (GBM) delta would look like in 2050 considering (i) existing policy direction within Bangladesh; (ii) trends over the previous 35 years; (iii) factors influencing the likelihood of these trends continuing for the next 35 years; (iv) externally imposed boundary conditions with respect to 
Table 10.2 Factors considered in the downscaling of socio-economic pathways for the development of local scenario narratives

\begin{tabular}{|c|c|c|}
\hline Well-being & Livelihood issues & Physical change \\
\hline Nutrition & Land use & Extreme weather events \\
\hline Food security & Crop types/diversification & Seasonality \\
\hline Access and availability & $\begin{array}{l}\text { Excessive and unplanned } \\
\text { use of fertilisers }\end{array}$ & $\begin{array}{l}\text { Frequency of natural } \\
\text { disaster }\end{array}$ \\
\hline Household equity & Pollution/sanitation & Arsenic \\
\hline Food prices & $\begin{array}{l}\text { Natural resource } \\
\text { management }\end{array}$ & Salinity \\
\hline Migration & $\begin{array}{l}\text { Changes in livelihoods } \\
\text { (e.g. crop to shrimp) }\end{array}$ & $\begin{array}{l}\text { Riverbank erosion } \\
\text { and sedimentation }\end{array}$ \\
\hline Remoteness & Local elite & Coastal defence \\
\hline $\begin{array}{l}\text { Coordination (sectoral } \\
\text { and geographical) }\end{array}$ & $\begin{array}{c}\text { Barriers to accessing } \\
\text { ecosystem services } \\
\text { in the Sundarbans }\end{array}$ & \\
\hline Capacity & Corruption/governance & \\
\hline $\begin{array}{l}\text { Lack of participation } \\
\text { and marginalisation } \\
\text { of the poor }\end{array}$ & $\begin{array}{l}\text { Implementation and } \\
\text { enforcement of } \\
\text { regulations }\end{array}$ & \\
\hline Disease & & \\
\hline
\end{tabular}

freshwater, temperature, storminess and sea-level rise; and (v) relevant international and global influences.

The list of issues was elaborated in far greater detail than had been expected and effectively downscaled the BAU scenario to the study area context. In effect therefore, the considerable effort required to elucidate each of the 100 or so elements constituted a downscaling of the SSP approach to a national context in a way that was considered credible by the cross-sectoral group of stakeholders present and maintained internal consistency. Unfortunately, it was not possible to undergo the same process for the other two scenarios due to time limitations, and adjustments had to be made, as discussed in the next section, during the next (narrative) stage in the scenario development. The completed matrix for BAU is shown in Table 10.3. 
Table 10.3 Completed matrix for the Business As Usual (BAU) scenario from the workshop on 22-23 October 2013

\begin{tabular}{ll}
\hline Natural resource management & Food security \\
\hline Salinity/freshwater & Availability and access \\
Freshwater $\downarrow+++$ & Rice (area) $\downarrow+$ \\
Ingress salinity $\uparrow$ & Rice (yield) $\uparrow+$ \\
Mangrove $\downarrow+$ & Others (area) $\uparrow+$ \\
Flow dynamics/riverbank erosion and & Others (yield) $\uparrow+$ \\
sedimentation & Storage $\uparrow++$ \\
Mech: Accretion $\uparrow+$ & Household storage $\uparrow+$ \\
Erosion $\uparrow+$ & Market access $\uparrow+$ \\
Water logging $\uparrow++$ and flooding $\uparrow++$ & Farmer knowledge $\uparrow+$ \\
Land use & Water security \\
Land use change rate $\uparrow++$ & Freshwater: \\
Rice production $\downarrow+$ & Quality $\downarrow++$ \\
Shrimp production $\uparrow+$ & Quantity $\downarrow++$ \\
Floodplain fisheries $\downarrow+++$ & Predictability $\downarrow+++$ \\
Coastal defence & Accessibility $\uparrow+$ \\
Infrastructure $\uparrow+$ & Nutrition \\
Maintenance/rehabilitation $\uparrow+$ & Food habit $\uparrow+$ \\
Mangrove/forest $\downarrow+$ & Pricing (\% income) $\downarrow+$ \\
Impact of extreme weather events & Protein $\uparrow$ \\
Asset damage $\uparrow++$ & Agriculture production systems/R\&D \\
Loss of life $\downarrow++$ & Efficient Fertiliser use $\uparrow+$ \\
Conservation effort $\uparrow+$ & R\&D/ technology $\uparrow++$ \\
Biodiversity $\downarrow+$ & Crop diversification $\uparrow+$ \\
Management (local involvement) $\uparrow+$ & Subsidies $\uparrow+$ \\
& Wheat production $\uparrow+$ \\
& Household equity \\
& Intra- $\uparrow+$ \\
& Inter- $\downarrow+$ \\
& Market dynamics \\
& Role of intermediaries $\downarrow+$ \\
Information technology (price information \\
& e.g. mobile phones) $\uparrow++$ \\
& Seasonality \\
& Shift in traditional practices \\
&
\end{tabular}

Key: $\downarrow$, expected deterioration; $\uparrow$, expected improvement; +, slight; ++, stronger; +++ , strong 


\begin{tabular}{|c|c|}
\hline Health/livelihoods/poverty & Governance \\
\hline $\begin{array}{l}\text { Migration } \\
\text { Net migration } \\
\text { (urban: rural ratio) } \uparrow++ \\
\text { Outmigration from project area } \uparrow++ \\
\text { Push } \uparrow++ \\
\text { Pull } \uparrow+++ \\
\text { Remoteness/communication/infrastructure } \\
\text { Infrastructure } \uparrow+ \\
\text { Communication } \uparrow++ \\
\text { W.A.S.H } \\
\text { Community } \uparrow+ \\
\text { Urban (formal) } \uparrow++ \\
\text { Urban (informal/slum) } \uparrow+ \\
\text { Water: Sanitation } \uparrow+ \\
\text { Changes in livelihoods } \\
\text { Diversification } \uparrow++ \\
\text { Utilisation of ecosystem services } \\
\text { Availability/Access } \uparrow \\
\text { Private sector: } \\
\text { Community } \downarrow++ \\
\text { (access ratio) } \\
\text { Private/community } \downarrow++ \\
\text { Disease } \\
\text { Non-communicable } \uparrow+ \\
\text { Water borne } \uparrow+ \\
\text { Vector borne } \uparrow+ \\
\text { Zoonotic } \uparrow+ \\
\text { Frequency and intensity of disasters } \\
\text { Gender } \\
\text { InFl DM } \uparrow+ \\
\text { Disaster risk reduction }+ \text { climate change } \\
\text { adaptation } \uparrow++ \\
\text { Access to natural resources/ecosystem } \\
\text { services } \uparrow+\end{array}$ & 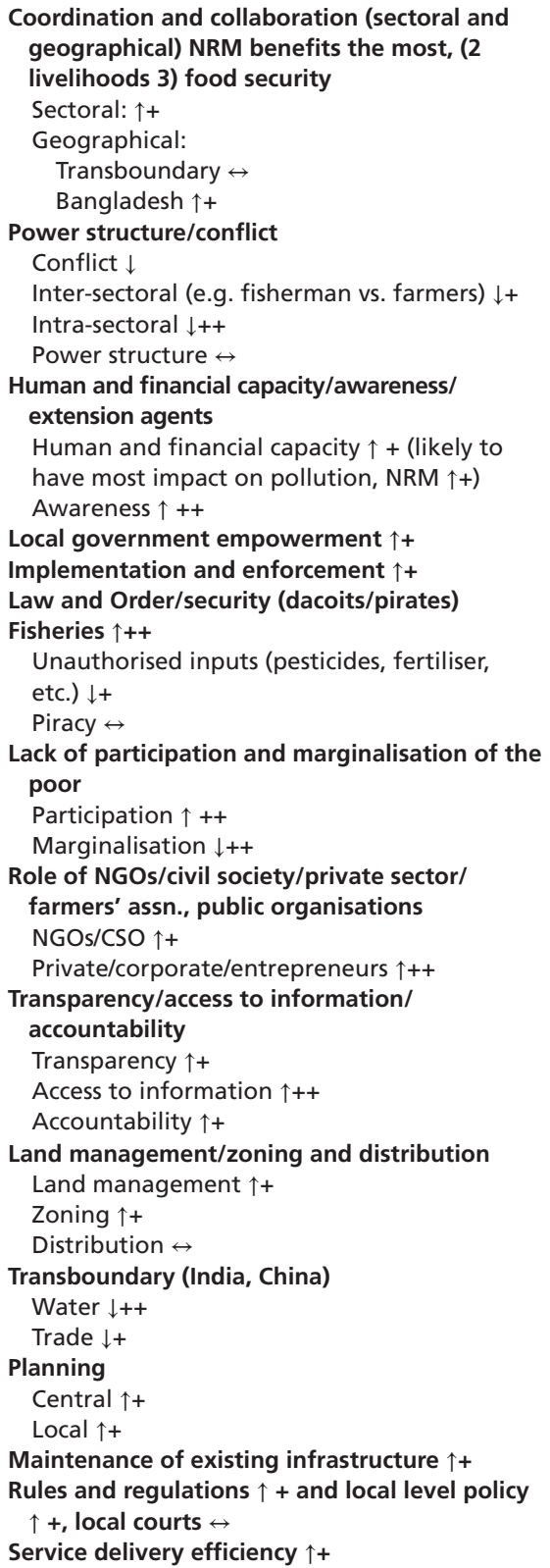 \\
\hline
\end{tabular}




\subsection{Scenario Narratives}

In order to translate the rough categories shown in Table 10.3 into the modelling efforts, they first had to be converted into a credible and representative narrative that could draw each element together in a more digestible format. A detailed narrative description was prepared to represent the detailed elaboration of the BAU scenario, with additional provisional narratives prepared by the project team for LS and MS, based on reasonable extrapolations of the BAU exposition. These three narratives were then presented at a further, larger workshop in May 2014. The main objective of the workshop, which was attended by 100 people, was to critically assess these detailed scenario narratives. The narratives needed to be stress-tested for credibility, internal consistency and for consistency between themselves-especially as only the BAU narrative was based on stakeholderderived information. The narratives re-framed the multitude of elements that were detailed in the first workshop (Table 10.3) into six categories: (i) land use, (ii) water, (iii) international cooperation, (iv) disaster management, (v) environmental management and (vi) quality of life and livelihoods. A coherent story was then developed by combining local, regional and global drivers and highlighting their impact for Bangladesh, and more particularly the study area in the south-west of the delta. This produces a greater alignment between the breadth of the matrix and the individual elements of the modelling and survey frameworks within the project.

Attendees were presented with a copy of the draft consolidated scenario narratives, and then split into three representative groups, mixing the diverse sectoral interests present. Each group was allocated one of the scenarios and given instructions (and some background) on how they should interpret the document and what they should do with it. Reports from the groups were made in plenary, consisting of identifying problems in their respective scenarios, highlighting potential policy or management interventions, and identifying barriers to policy implementation.

The scenario narratives stood up well to the sustained critical assessment of 100 experts. Many comments were made, and these were incorporated into the revised (and final) version of the narratives (see Appendix to this chapter). There was a generally lower level of consensus at the second stakeholder workshop than the first, although groups were still able to produce critical evaluation that was broadly agreed to by their members, and this 
level of disagreement could be explained simply by the fact that there were almost three times as many people present at the second meeting.

\subsection{Conclusions}

There was a great deal of value in conducting the scenario development in the manner described. Focusing on the elaboration of the BAU scenario during the initial stages allowed for better understanding of stakeholder views on the baseline situation current in Bangladesh, through reflection on both existing and recent historical trends. Stakeholders were often pleasantly surprised that they were able to maintain their involvement from the interview stage and then on to the workshops. This continuity provided evidence that the project was serious in taking their views into account. There was a general level of acceptance on the part of those attending workshops that the approach being taken was credible and was addressing the correct issues, even though there might be a strong element of disagreement over potential solutions or the magnitude of the problem. Over the duration of the project, it became clear that the credibility of research outputs was increased significantly by the fact that stakeholder views and inputs had been integral to each successive stage from the identification of the key issues right through to the modelling.

What also became clear was that availability of time was an issue for stakeholders, both from the perspective of project members trying to achieve too much within the limited time available during workshops but also because of the length of time that stakeholders were involved. In retrospect, the amount of information that stakeholders were expected to read and absorb was unrealistic: the narratives are complex documents of around 1,500 words each. This requires a considerable commitment on the part of stakeholders, who derive no other benefit from the process than the opportunity to discuss issues in a forum with others from outside their immediate sphere of contact, and the hope that they might acquire a greater understanding through the research outputs. Other alternative approaches may perform better-for example, by establishing a standing stakeholder expert group who could comment on technical detail, perhaps in return for a fee reflecting the degree of commitment needed-but it was not possible to follow these through in this project. 


\section{Appendix: Socio-economic Scenario Narratives for Bangladesh}

For future policy analysis, three socio-economic scenarios for the study area within Bangladesh were developed using the process described in Chaps. 9 and 10: Business As Usual (BAU), More Sustainable (MS) than BAU and Less Sustainable (LS) than BAU. The key aspects of each scenario are described in the following sections.

\section{Business as Usual}

\section{Land Use}

While the rate of change in land use has risen, there has been a gradual move to increased diversification of crops, for example to include more wheat and more vegetables, with continuing increases in shrimp production. Due to improvements in cultivation techniques (following decent hikes in the level of investment in research and development (R\&D)), more efficient use of fertilisers and pesticides, more targeted subsidy programmes and the use of high-yield varieties, yield per hectare for all crops has increased. Consequently, although cultivated areas given over to rice have decreased, overall production has risen.

Reductions in the level of resource conflict, between farmers and fishfarmers for example, along with the enhanced role of agricultural extension officers and more integrated rice/fish farming, provide positive contributions to increasing farm yield, along with higher levels of understanding of appropriate techniques on the part of farmers. Overall, these have the effect of cancelling out the detrimental impact of the changes in seasonality that have been experienced. Less helpfully, the combined effect of more intensive land use and patchy environmental management compliance has been an increase in land degradation.

The extent of coastal defence infrastructure has been enhanced, and natural flood barriers, such as the mangrove forest, have been slightly reduced in extent. Regulation of land use, including for floodplain and 
sectoral use zoning, has improved, as have levels of Central and devolved planning capacity.

\section{Water}

Improvements to the technology used for irrigation have been driven in part by a reduction in the amount of water coming down from India, with some reductions in predictability of availability and water quality. Predictability and availability are affected in part by increased river regulation in Nepal, India and China, with water pollution levels being driven by a combination of lower flows and higher levels of upstream industrial pollution. These improvements in irrigation have been to some extent offset by a significant overall increase in the use of water for agriculture.

Reduced freshwater flow and greater use of water for agriculture coupled with sea-level rise have heightened problems associated with saline intrusion in coastal areas. Despite this, provision of water to households, even in informal settlement areas, has improved to some extent, with better service delivery efficiency and infrastructure maintenance, following investment in water and sanitation service provision pursuant to achievement of development goals.

As a result of the decreasing flow in cross-border rivers, accretion is increasing, with erosion also increasing in the upper reaches of the delta.

Cooperation between water users across and within sectors has improved as a result of the relative scarcity of water and amplified levels of demand.

\section{International Cooperation}

Maintaining these levels of cooperation has not been aided by a deterioration in the extent to which basin states on the Ganges and Brahmaputra Rivers are cooperating, both with respect to water and in relation to trade. This is one of the most significant drivers of the reduction in transboundary flows. China has retained its observer status with the SAARC, and efforts to accord it full membership have not yet succeeded. 


\section{Disaster Management}

Along with increases in the extent of coastal defence and emergency infrastructure (such as cyclone shelters), efforts have been made to better maintain these constructions. Storage of harvested crops is substantially better than in 2013, through initiatives such as cyclone-resistant households. One of the benefits from these improvements has been a drastic reduction in the loss of life as a result of cyclones but there have also been relative increases in the level of economic damage caused.

\section{Environmental Management}

After decades of reasonably stable forest cover, the mangrove forest in the case area has suffered a small degree of encroachment. With reduced levels of water flow and increasing use of agricultural fertilisers across the country, for example, water quality has deteriorated to a certain extent, with governance capacity having improved to some degree but not sufficiently to control diffuse pollution.

Improvements to reticulated water supplies have not been quite adequate to compensate for this, and consequently levels of water-borne diseases have risen slightly. Protection of biodiversity has been detrimentally affected by a government focus on economic development, though efforts by civil society groups to remedy this have been stepped up. Coastal fisheries have dwindled due to the use of illegal and destructive gear, defiance of the ban period by the fishers and catching of undersized fish. Despite this, over-fishing continues as enforcement is weak.

\section{Quality of Life and Livelihoods}

The means by which households in the case areas maintain themselves have diversified significantly since 2013 , in addition to incorporating changes in cropping patterns. This includes substantial outward migration from the case areas, driven in part by rural pressures but more so by the economic attractions of urban areas such as Khulna, Chittagong and Dhaka. Population levels have remained largely static in coastal regions, though the population is ageing and the fertility rate has decreased. 
Long-term upward trends in literacy rates have continued, with education levels much improved on their 2014 levels.

Income levels are affected positively by a downturn in the importance of intermediaries in production processes, driven in part by rapid developments in mobile information technology and communications, price transparency and market access. Household storage of food has also increased, alleviating periods of scarcity somewhat. As a proportion of income, food is cheaper than it was in previous decades, with better eating habits and protein intake. However, this is offset by a slight increase in the incidence of non-communicable diseases and conditions, such as hypertension, with vector-borne (and zoonotic) diseases also rising, mainly as a result of rising temperatures and climatic conditions.

Increased household income coupled with continuing problems with significant disparities in income has resulted in a drop in inter-household equity, although this is complicated by broad advances in the participation of marginalised groups in society. Community power structures of patronage still govern much of rural society, but increasing involvement of the private sector and of Non-Governmental Orgaisations (NGOs) in local economic activities is changing the dynamic. Progress in the availability of mobile communications has enhanced awareness of legal rights and obligations, and improved access to information to a great degree. Enforcement of these rights has improved slightly, in line with some advancements in local enforcement capacity (through better local government empowerment), though these are somewhat restricted by a lack of progress in the capacity of local courts to process claims. This is highlighted by the disturbing lack of progress in tackling dakoits, which continues to blight the lives and economies of those who rely on fishing in particular.

\section{More Sustainable (MS) than BAU}

\section{Land Use}

Cultivated areas continued to be dominated by rice, but diversification of crops, especially the more intense cultivation of cash crops, driven by better access to markets (local and international) and effective agricultural exten- 
sion and educational outreach, has flourished. The environmental impact of shrimp cultivation has decreased substantially in extent due to the adoption of more sustainable techniques. Investment in agricultural research and development, along with adoption of more climate-smart agricultural techniques, has bolstered the use of high-yield varieties and more salt-tolerant varieties because of the need to reduce the area under crops, in the interests of environmental protection and natural flood defence.

This pressure to reduce or at least maintain no more than existing levels of agricultural land has been helped by the general stabilisation in population numbers and continuing (if slightly reduced) rural-urban migration. The proportion of urban against rural populations has risen steadily, thereby increasing the need for greater intensification of agriculture, a process that has not been alleviated by the global market place.

Greater intensification of agriculture has led to a slight deterioration in soil quality parameters. This has been offset by special development programmes that have produced new crop varieties that are suitable for coastal areas and less hazardous to soil health. The proportion of chemical fertilisers and pesticides used has declined compared to organic manure and integrated pest management.

Coastal protection has been extended, mainly through the efforts of the Delta plan, using a mixture of structural and non-structural options. Better zoning and monitoring of land use change has been beneficial, and the quality of land use management is now one of the key factors in the management of water use. Conflict over land use, including over ownership rights, has been very much reduced, due mainly to improvements in transparency and accountability through the land ownership cadastre and significant improvements to the local judicial hierarchy.

\section{Water}

Surface water flow patterns in the Ganges and Brahmaputra Rivers have varied over time, the arrival of the monsoon has become less predictable, and periods of drought have become extended due to the impacts of climate change. With better coordination between the states riparian to these rivers, however, management of water resources in Bangladesh has been able to make progress. The application of efficient land and water 
management practices and effective enforcement processes in India have enhanced predictability and availability of flow into Bangladesh and reduced levels of industrial and nutrient pollution.

Similar progress has taken place in Bangladesh: advances in communications technology provide regulators with detailed knowledge of river flow, level and quality in real time, with sophisticated modelling ability aiding the regulation of water use management. Legal frameworks allow water use to be varied in response to changes in resource availability, social and environmental priorities, and the better balancing of periods of flood and inter-annual scarcity.

In line with the stronger economic situation in Bangladesh, water and sewage service provision have been extended, and the careful planning of urban expansion has greatly restricted water pollution and reduced the incidence of water-borne disease. This has increased riverine fish stocks and rural engagement, with cultured and floodplain fish production also growing. Subsistence and artisanal fisheries have decreased but commercial fisheries have conversely increased, though the impact of this has been reduced through improved national and international governance of fisheries, which is now focused on sustainable coastal fishing. The successful achievement of the Millennium Development Goals, and subsequent iterations, has created a society where the vast majority of the population have access to piped water in their homes and improved sanitation facilities. This has been aided through excavation of ponds and tanks for conservation of water and the use of local technology for water treatment, such as pond sand filtering.

This improvement in drinking water availability, combined with the use of deeper aquifers in many places, has helped people avoid the problems associated with consumption of saline- and arsenic-contaminated water. Steps have been taken to ensure sustainable use and management of groundwater. There has been a major focus on conjunctive management of surface water and groundwater. Better monitoring of water table levels and groundwater / surface water interactions, and the ability to amend water use rights, is progressively improving the situation, although alternative supplies may still be difficult to apply.

Adequate upland flow has been ensured in water channels through the construction of the Ganges Barrage, which has helped preserve the coastal estuary ecosystem threatened by seawater intrusion. With the rapid 
development of upstream energy generation facilities, sediment transport downstream has been curtailed. This remains a major issue for the health of the delta, but basin states are working together to formulate a solution under the terms of existing water use treaties. The increased focus on sediment has resulted in improved tidal basin management and increased navigation potential.

As part of the general improvement in the management of water resources, principles of subsidiarity have been applied such that local management of water takes better account of upstream and downstream needs. Cooperation between these has therefore improved, helped by the cross-sectoral management of water resources as a whole and effective compliance monitoring. Levels of conflict between users and sectors and justiciable disagreements have consequently fallen.

\section{International Cooperation}

Relations have greatly improved between Bangladesh and India, and between India and China, a process driven partly by the regionalisation of energy markets and the critical importance of hydropower as a fossil fuel replacement. Coordination of electricity generation at basin level, taking account of downstream impacts in terms of flood alleviation, augmentation of dry season flow, improved scarcity management and the sediment requirements of the delta, has sprung from a regional realisation that the benefits of cooperation can be spread equitably and strategically throughout the basin. Improved transport links between Chittagong and both Kunming in China and the north-eastern states of India, coupled with investments in the delta area by both upstream countries, have resulted in greater trade links between the three nations and more effective abstraction and pollution control in the upper reaches of the Brahmaputra and Ganges Rivers.

Detailed multi- and bi-lateral treaties have been agreed by GBM basin states addressing water issues, closely linked to agreements on trade and energy distribution. Independent management authorities are in place, with detailed compliance and reporting requirements, and national legal and policy frameworks work to effect these agreements. 
International fisheries agreements relevant to the Bay of Bengal have led to greater food security for coastal fishermen, and improved enforcement has reduced levels of sea piracy.

\section{Disaster Management}

With the gradual decentralisation of Bangladesh, drawing populations from Dhaka to regional hubs, disaster management has also been further devolved, with disaster risk reduction being linked closely with adaptation. Disaster forecasting and preparedness is of world-standard quality, benefiting from advances in communication technology. The network of cyclone shelters, financed primarily by local and regional authorities and through private sector initiatives, has evolved such that the impact of increasing storm surges has been largely negated, with loss of life being maintained at relatively minimal levels.

Adaptive agri- and aqua-culture systems have also helped to substantially reduce production losses during and post disaster and aided postdisaster resilience. Storage of local crops and livestock has been significantly improved, with effective local insurance schemes in place to ameliorate livelihood losses. Improved transport networks between urban centres has also had a positive effect on the response times of emergency and remediation teams. The successful and ongoing implementation of the Delta Plan has been advantageous for disaster impact reduction.

\section{Environmental Management}

Mangrove forest cover has been maintained in the Sundarbans at the levels seen earlier in the century, augmented by active planting programmes that have taken place as part of the Delta Plan. The result has been an increase in terrestrial and aquatic biodiversity as the mangrove belt has expanded along the coast. The forest has benefited from improvements in water quality, but the balancing of livelihood maintenance for those living in the vicinity, and protection of biodiversity, remains problematic. 
Improvements in the economic situation for those living in the case areas has reduced the need to use the Sundarbans directly for their livelihood maintenance, but a significant increase in 'eco-tourism', some of it still unregulated, continues to complicate matters.

Soil and water health has increased overall, driven by improvements in water quality and the use of state-of-the-art agricultural techniques. Although salt water intrusion remains problematic, better surface/ groundwater management and improved polder maintenance have helped to keep this in check.

\section{Quality of Life and Livelihoods}

Standards of education in the countryside have leapt exponentially, especially for females. This, coupled with agricultural intensification and the managed expansion of decentralised urban hubs, has perpetuated general levels of migration away from the countryside. The gradual erosion of the traditional village and regional hierarchies and power structures has opened up a wide variety of possible livelihood alternatives for those in the case areas. The principal agents of this erosion have been the astonishingly rapid development of mobile technology (providing greater visibility for those working against the law), more effective enforcement mechanisms resulting from economic development, and improvements in educational ability stemming from enforced mandatory standards.

As regards population structure, fertility and mortality rates have been declining for some time now, and, critically, levels of out-migration to regional urban hubs have gone down slightly. The consequence of this is that population levels have dropped very slightly from their 2014 levels, but the structure has changed since then such that there are proportionately significantly more people aged over 65 and substantially fewer aged under 14.

The availability of credit has improved significantly, through a profusion of public and private providers, with reliance on local moneylenders non-existent. The availability of insurance for all has had significant impacts on the resilience of those in the case areas, reducing vulnerability to flood events, for example. Better access to local markets especially, combined with the diversification of crops, has improved the health of the 
population, although meat is very expensive and protein intake remains problematic for some. Incidence of hypertension has risen alarmingly as populations have grown more sedentary, with higher temperatures discouraging physical activity still further.

Levels of inter-household inequity have fallen in the case areas, as local remittances have increased, the gap between the richest elites and those on average incomes has narrowed with the crumbling of traditional social structures, and income levels for females have gone up (a process that has been mirrored at regional level, reducing income disparities more generally). This has also limited intra-household inequity, with male family members finding it progressively more difficult to maintain economic hegemony over others in their families. The number of NGOs has gone down over time, but their effectiveness has risen, in part because they are more coordinated, and in part because they are better positioned to take advantage of mobile technology.

\section{Less Sustainable (LS) than BAU}

\section{Land Use}

Areas that were formerly cultivated have been given over to a mixture of brackish shrimp and, to a lesser extent, rice, respectively serving the export market and local consumption needs of subsistence farmers.

Freshwater prawn production has decreased. Brackish shrimp production has taken increasingly large shares of cultivable land, pushing subsistence farm land into areas more vulnerable to inundation and less protected by coastal engineering infrastructure. More intensive rice cultivation is characterised by high levels of fertiliser use, although yields per hectare have not risen as fast as they might because R\&D priorities have focused on producing shrimp for the richest nations.

Inter-sectoral cooperation (e.g. between fishermen and farmers) is on the decrease, and intra-sectoral conflict between the owners of industrial farming concerns (and their tenant farmers) and subsistence farmers is growing. Scarcity of available secure land and the difficulty in obtaining clean water for irrigation from reduced water resources exacerbates 
disagreements. Agricultural extension officers prioritise the production of exportable crops, leaving subsistence farmers struggling to take advantage of new techniques and subsidies, and subject to heightened levels of insecurity as seasonal cropping patterns change with the climate.

In addition to the encroachment of brackish shrimp production, mangrove forests have been slowly sacrificed to commercial agriculture, salt pans and unplanned urban spread, as a result of a combination of the government need for hard currency, increasing soil and surface water salinity, and population migration from rural poverty. Vulnerability to flooding has therefore increased as natural barriers have been removed and existing embankments are poorly managed due to lack of financial resources and sectoral conflicts. While floodplain and land use zoning is in place, implementation levels are low because of a lack of enforcement.

\section{Water}

Water resources have decreased significantly as a result of a combination of a number of factors: the rapid development of dams and barrages constructed upstream for the purposes of energy production; flood alleviation and irrigation schemes; the impact of the now fully-implemented Inter-linking Rivers Project; and large-scale transfers from the Brahmaputra River in China to provide water for northern irrigation schemes and domestic consumers in Beijing. The efficiency of industrial agricultural irrigation is high, but this is heavily reliant on the unregulated use of groundwater (driven in part by energy subsidies that fuel pumping), necessary because of the lack of surface water flow and the need to access higher-quality water untainted by polluted surface water.

The unfettered use of groundwater from the less saline shallow aquifers in the northern part of the southwest coastal zone, coupled with the rise in sea level, has hastened saline intrusion of aquifers. The spread of unplanned urban settlements, especially in Dhaka, driven by population growth in the country as a whole and by out-migration from coastal areas, has adversely affected water quality downstream as a result of a lack of sewage treatment works. Early advances in achieving development goals have been undermined by this population growth. Although 
economic gains have to a certain extent continued, they have not been sufficient to counteract changes in population patterns and location.

Levels of cooperation between upstream and downstream districts have decreased within Bangladesh, mirroring the rise in inter-sectoral conflict between land and water users. As land use ownership patterns have moved to a greater proportion of tenant farmers, local water management institutions have found themselves toothless and ineffective, with longer-term management decisions being compromised by shortterm priorities.

\section{International Cooperation}

Cooperation in terms of access to global markets has increased in some ways, although exports are very much higher than imports. Cooperation at the more regional level has, however, deteriorated, with basin coriparians in direct competition with each other, especially with respect to agricultural commodities. This has destroyed efforts to manage regional watercourses at the basin level, with corresponding impacts on the amount of freshwater flowing into Bangladesh. Remaining basin-level governance efforts are focused on maintaining flows needed for commercial agriculture and aquaculture.

\section{Disaster Management}

Although there has been some increase in the extent of coastal defence and emergency infrastructure (such as cyclone shelters), maintenance efforts have concentrated on protecting agricultural investments. This has resulted in a creeping process of polderisation in downstream areas, although storage of harvested subsistence crops has increased at village level. These are seldom strong enough to withstand the pressures from cyclones and storm surges, however. Loss of life as a result of these pressures remains low, but the disproportionately high numbers of female deaths mean that impacts on livelihoods are drastic. 


\section{Environmental Management}

Water quality has been detrimentally affected by the relatively low surface water flows coming into Bangladesh and diffuse pollution as a consequence of the liberal use of fertilisers both upstream and in Bangladesh itself. This has been compounded by the effluent resulting from the expansion of unplanned informal settlements. Encroachment in areas previously covered by mangrove has continued, with commensurate effects on biodiversity and the capacity of supporting ecosystem services. Civil society efforts to combat loss of biodiversity have been dissipated by a lack of inter- and intra-sectoral coherence, although the incidence of poverty has been responsible for an increase in the numbers of Civil Society Organisation (CSOs). Fish stocks in coastal rivers are under severe pressure, as are coastal fisheries, partly as a result of irresponsible shrimp farming methods and partly because of poor regulation and enforcement.

Levels of water-borne diseases have risen because poorer families have few alternatives to using contaminated surface water for domestic use: groundwater levels have fallen below the limits of cheap pumps, and saltwater intrusion is common.

\section{Quality of Life and Livelihoods}

The embedded power structures characteristic of rural Bangladesh at the beginning of the twenty-first century have become even more entrenched as local elites take advantage of the economic gains to be made through the production of brackish shrimp and the low cost of labour. Outward migration to urban centres within Bangladesh, particularly Dhaka, has risen as populations have grown and commercialisation of agriculture has reduced still further labour needs in rural areas. Ever-expanding urban areas and low employment opportunities in cities mean that monetary transfers back to rural areas by migrant workers have reduced markedly, and migration out of Bangladesh to traditional remittance-generating regions has become more challenging as the traditional international migration destinations are now much more selective about immigration because of the sheer volume of immigrant labour sources globally. 
Population levels in the case areas have not changed drastically in recent decades, but this is only because higher fertility levels have been offset by stubbornly high mortality rates and the marked increase in outward migration. Livelihood sources also have not changed greatly, though the number of older tenant farmers has risen, as people of working age have moved to industrial farms for employment, leaving the young and old behind. Remittances from family members who have moved abroad or to urban centres have diminished, but the capacity of the land to support the growing population, coupled with climate-driven changes in cropping cycles, has meant that such migration has become a necessity.

This is exacerbated by the outward movement of those whose livelihoods have been destroyed by storms. Those living in the largely unplanned informal urban settlements are often forced to live in a handto-mouth way, with only the luckiest progressing on to secure jobs. Family structures are weaker than they were 30 or 40 years ago, although family networks are of great importance in maintaining remittance levels at even their current position.

Those working in industrial agricultural operations enjoy greater security of income, although salaries are kept low by the constant need to keep Bangladesh competitive in a very difficult market. Subsistence farmers remain almost completely outside national and international markets, and are unable to take advantage of technological advances in mobile telecommunications. The main developing market for those engaged in business outside the major agricultural conglomerates lies in West Bengal, with cross-border trade in the area between Kolkata and Khulna growing rapidly, a process aided by the gradual destruction of the Sundarban mangroves. Electricity distribution networks are unreliable especially in coastal areas, an ongoing problem caused mainly by the poverty in the area and the high frequency of damage by storms. Food and protein scarcity in subsistence areas have become a problem, leading to an increase in open water fishing by residents, despite the risks. The incidence of vectorborne (and zoonotic) diseases has risen, mainly as a result of rising temperatures and climatic conditions.

The erosion of family structures has, surprisingly, raised levels of intrahousehold equity as earners of any kind have become more important, but inter-household equity has dropped as the split between subsistence 
and tenant farmers has deepened. More urgent efforts by NGOs and CSOs to help the very poorest have been beneficial in terms of encouraging broader civic participation, but the power differential between largely locally-focused groups and the large-scale farming concerns has rendered the work of the former largely irrelevant. Earlier weaknesses in local dispute resolution and access to rights have multiplied with the involvement of local elites in wealth development activities. Creeping centralisation over a period of decades has left an emboldened local governance framework characterised by lack of accountability and transparency, and an absence of central oversight. Backlogs in local courts have fallen, but this is the result not of greater efficiency but of an increasing fatalism on the part of the aggrieved population.

The ability of the poorest to access lending facilities is very restricted as formal institutions are reluctant to lend. The poor remain reliant on lending at usurious rates by local lenders. The increased incidence of piracy further affects livelihoods, especially those of fishers, whose numbers are dwindling as stocks collapse and migration becomes more attractive.

\section{Note}

1. A full list of the stakeholders, along with details of their attendance at project meetings, is available at www.espadeltas.net

\section{References}

Allan, A.A., M. Lim, N. Islam, and H. Huq. 2013. Livelihoods and ecosystem service provision in the southwest coastal zone of Bangladesh: An analysis of legal, governance and management issues. ESPA Deltas Working Paper \#1. University of Dundee. http://espadelta.net/resources_/working_papers/. Accessed 3 Oct 2016.

Arnell, N.W., T. Kram, T.R. Carter, K.L. Ebi, J. Edmonds, S. Hallegatte, E. Kriegler, R. Mathur, B. O’Neill, K. Riahi, H. Winkler, D. Van Vuuren, and T. Zwickel. 2011. A framework for a new generation of socioeconomic scenarios for climate change impact, adaptation, vulnerability and mitigation 
research. Working Paper. https://www2.cgd.ucar.edu/sites/default/files/iconics/Scenario_FrameworkPaper_15aug11.pdf. Accessed 20 July 2016.

O’Neill, B.C., T.R. Carter, K.L. Ebi, J. Edmonds, S. Hallegatte, E. KempBenedict, E. Kriegler, L.O. Mearns, R.H. Moss, K. Riahi, B. Van Ruijven, and D. Van Vuuren. 2012. Meeting report of the workshop on the nature and use of new socio-economic pathways for climate change research, November 2-4, 2011. Boulder: National Center for Atmospheric Research (NCAR). http://www2. cgd.ucar.edu/research/iconics/events/20111102. Accessed 20 July 2016.

Payne, G., and J. Payne. 2004. Key concepts in social research. London: Sage.

Prell, C., K. Hubacek, and M. Reed. 2009. Stakeholder analysis and social network analysis in natural resource management. Society and Natural Resources 22 (6): 501-518. https://doi.org/10.1080/08941920802199202.

Reed, M.S., A. Graves, N. Dandy, H. Posthumus, K. Hubacek, J. Morris, C. Prell, C.H. Quinn, and L.C. Stringer. 2009. Who's in and why? A typology of stakeholder analysis methods for natural resource management. Journal of Environmental Management 90 (5): 1933-1949. https://doi. org/10.1016/j.jenvman.2009.01.001.

Open Access This chapter is licensed under the terms of the Creative Commons Attribution 4.0 International License (http://creativecommons.org/licenses/ by/4.0/), which permits use, sharing, adaptation, distribution and reproduction in any medium or format, as long as you give appropriate credit to the original author(s) and the source, provide a link to the Creative Commons license and indicate if changes were made.

The images or other third party material in this chapter are included in the chapter's Creative Commons license, unless indicated otherwise in a credit line to the material. If material is not included in the chapter's Creative Commons license and your intended use is not permitted by statutory regulation or exceeds the permitted use, you will need to obtain permission directly from the copyright holder.

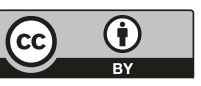

